\title{
Lab-on-Chips for Cellomics
}

\section{Micro and Nanotechnologies for Life Science}

Edited by

Helene Andersson

Royal Institute of Technology,

Microsystem Technology, Stockholm, Sweden

and

Albert van den Berg

University of Twente,

Enschede, The Netherlands

照 Springer 
A C.I.P. Catalogue record for this book is available from the Library of Congress.

ISBN 978-1-4020-6562-0 (PB)

ISBN 978-1-4020-2860-1 (HB)

ISBN 978-1-4020-2975-2 (e-book)

Published by Springer,

P.O. Box 17, 3300 AA Dordrecht, The Netherlands.

www.springer.com

Printed on acid-free paper
All Rights Reserved
(C) 2004 Springer
No part of this work may be reproduced, stored in a retrieval system, or transmitted in any form or by any means, electronic, mechanical, photocopying, microfilming, recording or otherwise, without written permission from the Publisher, with the exception of any material supplied specifically for the purpose of being entered and executed on a computer system, for exclusive use by the purchaser of the work. 


\section{CONTENTS}

List of Contributors vii

Preface xiii

Chapter 1

Microfluidic devices for cellomics

H. Andersson and A. van den Berg

Chapter 2

Pretreatment of biological sample for microchip analysis

J. Ferrance and J. Landers

\section{Chapter 3}

Liposomes as model cellular systems

L. Locascio, W. Vreeland, A. Jahn and M. Gaitan

\section{Chapter 4}

Versatile chip-based tool for the controlled manipulation of microparticles in biology using high frequency

electromagnetic fields

C. Duschl, P. Geggier, M. Jäger, M. Stelzle, T. Müller,

T. Schnelle and G. Fuhr,

Chapter 5

Micro-electroporation in cellomics

B. Rubinsky 
Chapter 6

Patch-clamp microsystems

T. Lehnert and M. Gijs

\section{Chapter 7}

Using lab-on-a-chip technologies to understand cellular mechanotransduction

D. Pirone and C. Chen

\section{Chapter 8}

Analysis of apoptosis on chip

F. Wolbers, C. Haanen, H. Andersson, A. van den Berg and

I. Vermes

Chapter 9

On-chip single-cell cultivation systems

K. Yasuda

\section{Chapter 10}

Human embryonic stem cells and microfluidics

V. Abhyankar and D. Beebe

\section{Chapter 11}

Cellular and subcellular analysis on chip

$\mathrm{H}$. Lu and $\mathrm{K}$. Jensen

\section{Chapter 12}

Microfluidic cell-culture devices

Y. Sakai, E. Leclerc, and T. Fujii

\section{Chapter 13}

Micromachined bioreactor for in vitro cell self-assembly and 3D tissue formation

K. Domansky, A. Sivaraman and L. Griffith

Color plates

Index 


\title{
LIST OF CONTRIBUTORS
}

\author{
EDITORS \\ H. Andersson \\ Royal Institute of Technology \\ Microsystem Technology \\ 10044 Stockholm, Sweden \\ and \\ MESA+ Institute \\ University of Twente, BIOS \\ Enschede, The Netherlands
}
A. van den Berg
MESA+ Institute
University of Twente, BIOS
Enschede, The Netherlands

\section{CONTRIBUTORS}

V. Abhyankar

Dept. of Biomedical engineering

Univeristy of Wisconsin

Madison, WI

USA

D. Beebe

Dept. of Biomedical engineering

Univeristy of Wisconsin

Madison, WI

USA 
viii

C. Chen

Department of Biomedical Engineering

Johns Hopkins University,

Baltimore, MD

USA

K. Domansky

Biological Engineering Division and

Biotechnology Process Engineering Center,

Massachusetts Institute of Technology

Cambridge, MA

USA

C. Duschl

Fraunhofer-Institut für Biomedizinische Technik

Berlin, Germany

J. Ferrance

Departments of Chemistry and Pathology

University of Virginia,

Charlottesville, VA

USA

G. R. Fuhr

Fraunhofer-Institut für Biomedizinische Technik

Berlin, Germany

T. Fujii

Institute of Industrial Science

Univerisity of Tokyo

Tokyo, Japan

M. Gaitan

Semiconductor Electronics Division

National Institute of Standards and Technology

Gaithersburg, MD

USA

P. Geggier

Fraunhofer-Institut für Biomedizinische Technik

Berlin, Germany 


\title{
M. Gijs
}

Swiss Federal Institute of Technology Lausanne (EPFL)

Institute of Microelectronics and Microsystems

Lausanne, Switzerland

L. Griffith

Biological Engineering Division,

Biotechnology Process Engineering Center and

Department of Mechanical Engineering

Massachusetts Institute of Technology

Cambridge, MA

USA

C. Haanen

Department of Clinical Chemistry

Medical Spectrum Twente, Hospital Group

The Netherlands

\section{Jäger}

Fraunhofer-Institut für Biomedizinische Technik

Berlin, Germany

A. Jahn

Semiconductor Electronics Division

National Institute of Standards and Technology

Gaithersburg, MD

USA

K. Jensen

Department of Chemical Engineering

Massachusetts Institute of Technology

Cambridge, MA

USA

\author{
J. Landers \\ Departments of Chemistry and Pathology \\ University of Virginia, \\ Charlottesville, VA \\ USA
}


E. Leclerc

CNRS/UMR 6600

Université Technologique de Compiégne.

France

T. Lehnert

Swiss Federal Institute of Technology Lausanne (EPFL)

Institute of Microelectronics and Microsystems

Lausanne, Switzerland

L. Locascio

Analytical Chemistry Division

National Institute of Standards and Technology

Gaithersburg, MD

USA

H. $\mathrm{Lu}$

Department of Anatomy

University of California

San Francisco, CA

USA

T. Müller

Evotec Technologies GmbH,

Berlin, Germany

D. Pirone

Johns Hopkins University,

Baltimore, MD

USA

B. Rubinsky

Department of Mechanical Engineering and

Department of Bioengineering

University of California at Berkeley

Berkeley, CA

USA

Y. Sakai

Institute of Industrial Science

Univerisity of Tokyo

Tokyo, Japan 

A. Sivaraman
Biotechnology Process Engineering Center and
Department of Chemical Engineering
Massachusetts Institute of Technology,
Cambridge, MA
USA
T. Schnelle
Evotec Technologies GmbH
Berlin, Germany

M. Stelzle

Naturwissenschaftliches und Medizinisches

Institut an der Universität Tübingen

Reutlingen, Germany

I. Vermes

Department of Clinical Chemistry

Medical Spectrum Twente, Hospital Group

The Netherlands

W. Vreeland

Analytical Chemistry Division

National Institute of Standards and Technology

Gaithersburg, MD

USA

F. Wolbers

Department of Clinical Chemistry

Medical Spectrum Twente, Hospital Group

The Netherlands

and

MESA+ Institute

University Twente, BIOS

Enschede, The Netherlands

K. Yasuda

Department of Life Sciences

Graduate School of Arts and Sciences

The University of Tokyo

Tokyo, Japan 


\section{PREFACE}

Dear reader,

In the past few years we have observed an interesting mutual interest of two fields of research and development in each other. Life sciences area researchers discovered the opportunities offered my micro- and nanotechnology, while people from the microfluidics and BIOMEMS area discovered the application potential of these technologies in cell biology. Unfortunately, these two research communities share little in common: they read and publish in different scientific journals, have incompatible jargons, attend separate conferences, and have a different scientific approach and culture. This is most strikingly illustrated when you give a MEMS researcher some cells to experiment with, or hand over a couple of chips to a cell biologist. Or imagine explaining a microengineer different intracellular apoptotic pathway or a cell biologist about tensile stress in underetched LPCVD membranes.

And yet, there is an enormous potential of combining the expertises available in these two fields. It is our goal to illustrate this potential with this book focusing on microfluidics technologies for "cellomics", research on or with cells. In our view, the field is still too immature to compile a textbook for students, and this volume is rather meant to be a collection of first class papers of leaders in this emerging field. This volume will enable researchers from both communities to get a rapid "state of the art" overview, and also to get an impression what kind of possibilities this area offers. Micro- and nanotechnologists will get inspiration about applications, life science researchers about technological capabilities. 
We have tried to collect a reasonable mixture of representatives of these two fields, and we are very proud that all authors have been willing and capable of preparing their manuscripts in a record-breaking time frame.

The book starts off with an overview chapter by ourselves, providing the reader with ample references on recent publications in this area and including an attempt to classify the field. In chapter 2, James Landers et al. gives a thorough description of the various pretreatment steps that are in use for biological samples, whereas Laurie Locascio et al. provides several original examples of model systems for cells in chapter 3. The next few chapters deal with examples of cell manipulation; we are delighted to have a contribution from Gunther Fuhr's group on cell trapping and sorting, as we are very happy too with the excellent contribution from Boris Rubinsky about electrical cell manipulation (electroporation,) in chapter 5. Martin Gijs et al. describe one of the most promising commercial microstructure for cells, a patch-clamp system on chip in chapter 6 . We believe that this particular application is one of the nicest examples of how microstructures can be beneficial for cell applications.

Mechanical manipulation and analysis of cells using microstructures is treated with various creative examples in chapter 7 by Chris Chen et al. Suppression or enhancement of apoptosis is known to cause or contribute to many diseases such as cancer and diabetes. However, there are no tools available today that enable non-invasive real time analysis of apoptosis. In chapter 8, Istvan Vermes et al give a tutorial introduction and some prospects on how lab-on-chip technologies could contribute to analysis of apoptosis. Another potential direction is shown in chapter 9 by Kenji Yasuda, who nicely describes behavior and exploitation of cells in interaction, arranged in any kind of interconnected network. The very recent, and not uncontroversial potential of stem cells in combination with microstructures is treated in chapter 10 by Dave Beebe et al, while a very interesting new trend to analyze intracellular phenomena is presented in chapter 11 by Klavs Jensen et al. as an example of what may become a socalled "Lab-in-a-Cell" in the future. Teruo Fujii et al. proof that microfluidic networks have great potential for studying behavior of (large) single cells, and enable investigation of chemical signaling in chapter 12. Finally, in the last chapter 13, Linda Griffith et al. give a preliminary example of what might be in the future an even more complex and sophisticated application area of microfluidics and cells, namely the area of tissue engineering. From this chapter in particular, we believe that MEMS engineers may obtain inspiration for new research directions such as real 3D microfluidics. 
Enough explanation and introduction; we hope and actually are convinced that this book contains ample material for you to become even more motivated and stimulated to work in this exciting and colorful field of research. We also believe that, after the successes of MEMS for physical and analytical (bio)chemical applications, this book will be a nice illustration of the next important application field, MEMS for cellomics.

With wish you a very enjoyable and inspiring reading!

Helene Andersson and Albert van den Berg (should be hand written)

Enschede, Faculty Club, June 2004. 